\title{
Effects of Impurity Content on the Sintering Characteristics of Plasma-Sprayed Zirconia
}

\author{
S. Paul, A. Cipitria, I.O. Golosnoy, L. Xie, M.R. Dorfman, and T.W. Clyne
}

(Submitted April 3, 2007; in revised form June 25, 2007)

\begin{abstract}
Yttria-stabilized zirconia powders, containing different levels of $\mathrm{SiO}_{2}$ and $\mathrm{Al}_{2} \mathrm{O}_{3}$, have been plasma sprayed onto metallic substrates. The coatings were detached from their substrates and a dilatometer was used to monitor the dimensional changes they exhibited during prolonged heat treatments. It was found that specimens containing higher levels of silica and alumina exhibited higher rates of linear contraction, in both in-plane and through-thickness directions. The in-plane stiffness and the through-thickness thermal conductivity were also measured after different heat treatments and these were found to increase at a greater rate for specimens with higher impurity (silica and alumina) levels. Changes in the pore architecture during heat treatments were studied using Mercury Intrusion Porosimetry (MIP). Fine scale porosity $(<\sim 50 \mathrm{~nm})$ was found to be sharply reduced even by relatively short heat treatments. This is correlated with improvements in inter-splat bonding and partial healing of intra-splat microcracks, which are responsible for the observed changes in stiffness and conductivity, as well as the dimensional changes.
\end{abstract}

Keywords apparent Young's modulus, plasma spray coatings, porous material, sintering, thermal conductivity

\section{Introduction}

Plasma-sprayed ceramic coatings are widely used for thermal and environmental protection, particularly in gas turbines (Ref 1-4). Thermal barrier coatings (TBCs) are particularly critical in these applications. Yttria-stabilized zirconia (YSZ) is the most commonly used coating material in conjunction with a bond coat layer. A typical as-sprayed microstructure is shown in Fig. 1. The coating is built up by successive deposition of over-lapping splats, often with relatively poor bonding between them. Individual splats tend to exhibit microcracks within them, caused by hindered thermal contraction during quenching of the splat immediately after impact. The pore structure, in the form of inter-splat voids, intra-splat microcracks and other, coarser and more globular pores, has a strong influence on coating properties (see below).

This article is an invited paper selected from presentations at the 2007 International Thermal Spray Conference and has been expanded from the original presentation. It is simultaneously published in Global Coating Solutions, Proceedings of the 2007 International Thermal Spray Conference, Beijing, China, May 1416, 2007, Basil R. Marple, Margaret M. Hyland, Yuk-Chiu Lau, Chang-Jiu Li, Rogerio S. Lima, and Ghislain Montavon, Ed., ASM International, Materials Park, OH, 2007.

S. Paul, A. Cipitria, I.O. Golosnoy, and T.W. Clyne, Department of Materials Science \& Metallurgy, Cambridge University, Pembroke Street, Cambridge, CB2 3QZ, UK; and L. Xie and M.R. Dorfman, Sulzer Metco (US) Inc., Westbury, NY, USA. Contact e-mail: sp367@cam.ac.uk.
Improved techniques have recently been developed for characterization of the fine scale pore content and architecture in coatings such as these, particularly small angle neutron scattering (SANS) (Ref 5-8), small angle x-ray scattering (Ref 9) and mercury intrusion porosimetry (MIP) (Ref 10).

It is now well established (Ref 11-16) that both the pore architecture and other microstructural features (grain size, phase constitution, etc.) of these coatings can be significantly affected by prolonged exposure to high temperature. An illustration of how both inter-splat voids and intra-splat microcracks can coarsen and partially heal via sintering phenomena at elevated temperature is provided by the pair of micrographs shown in Fig. 2. While the temperature used for the heat treatment to which the coating in Fig. 2(b) was subjected was relatively high $\left(1400{ }^{\circ} \mathrm{C}\right)$, the period concerned $(10 \mathrm{~h})$ was short compared to those common under service conditions. Moreover, as the operating temperatures of gas turbines are progressively increased, the need for coatings to remain microstructurally and thermo-mechanically stable when subjected to temperatures of this order is becoming more pressing. On the other hand, it should be recognized that most such experimental work has been carried out on coatings that have been detached from their substrates. It has been pointed out (Ref 17) that the constraint imposed by attachment to a metallic substrate tends to inhibit these sintering (and associated contraction) effects in the coating, although they can still be significant.

There is concern that such sintering-induced changes can occur under service conditions and may adversely affect the protective function of the coating. Of course, sintering is not the only potential source of degradation. Stover and Funke (Ref 18), in reviewing the future of TBCs in power generation gas turbines, identify residual stress generation, thermo-mechanical loading, cyclic strain loads, creep, sintering and interface oxidation as the key 


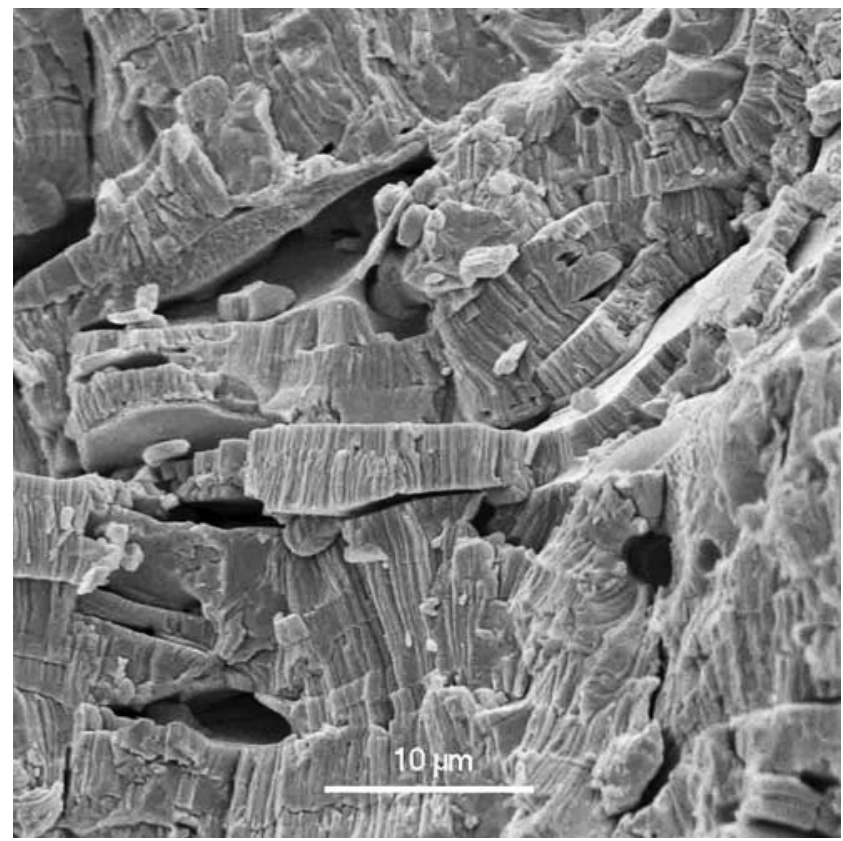

Fig. 1 SEM micrograph of the fracture surface of a YttriaStabilized Zirconia (YSZ) coating produced by atmospheric plasma spraying (APS)

phenomena likely to cause coating failure and spallation. In general, other authors (Ref 3,19$)$ are in agreement with this analysis (for both plasma sprayed and PVD coatings). It is important to appreciate, however, that most of these effects are likely to be exacerbated by the substantial stiffening commonly associated (Ref 14, 17, 20-22) with sintering phenomena, so it is not only the shrinkage caused by sintering that is likely to be deleterious. Moreover, sintering can also cause significant increases in the through-thickness thermal conductivity (Ref 6, 20, 23-25), reducing the thermal protection offered to the substrate. Finally, it is well established (Ref 26) that the erosion resistance of these coatings tends to be impaired by sintering effects.

There is relatively little information available about the influence of composition on the sintering behavior of these coatings. There have been a few studies (Ref 23, 25) covering the effects of stabilizers (dopants), but in general little is known about whether significant improvements in sintering resistance can be achieved by this type of compositional control. There have also been some reports (Ref 27-29) concerned with the effects of impurities, notably the presence of silica and/or alumina, which are the contaminants most likely to be present in these powders at significant levels. In general, these studies have indicated that sintering tends to be accelerated by the presence of these species. For example, Chen et al. (Ref 27) found that 3 wt. $\% \mathrm{SiO}_{2}$ significantly enhanced the sintering rate, and this was attributed to liquid sintering-i.e., to the formation of a vitreous, low viscosity phase, which would be able to effect mass redistribution via capillarity forces, rather than just by (surface, interface, or lattice) diffusion. This is consistent with the work of Stemmer et al. (Ref 30), who
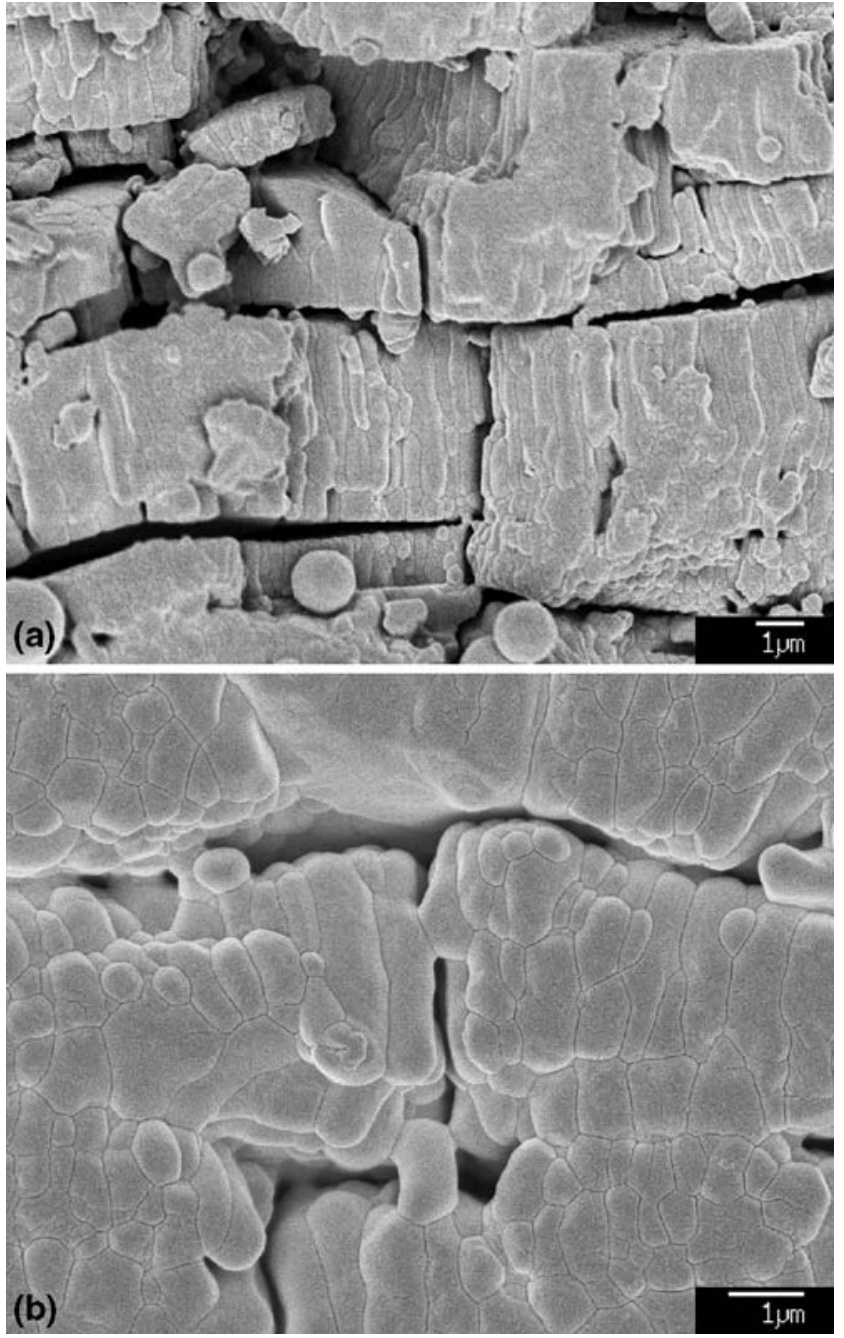

Fig. 2 SEM micrographs of fracture surfaces of a YSZ coating produced by APS, (a) as-sprayed and (b) after a heat treatment of $10 \mathrm{~h}$ at $1400{ }^{\circ} \mathrm{C}$

used high-resolution TEM and EELS to report that samples with $\sim 0.1$ wt. $\% \mathrm{SiO}_{2}$ exhibited an amorphous silicate phase at triple grain junctions. However, there has been little or no systematic work on whether worthwhile reductions in sintering rates can be achieved via impurity control. The present article addresses both this issue and the question whether coating properties are significantly affected by impurity content. Both dilatometry during heat treatment and post-treatment measurement of properties are used to investigate this.

\section{Experimental Procedures}

\subsection{Production of Plasma-Sprayed Coatings}

Coatings were produced by atmospheric plasma spraying (APS), under the conditions listed in Table 1. The compositions of the zirconia powders used are given in Table 2. Spraying was carried out onto $1.5 \mathrm{~mm}$ thick 
Table 1 Plasma spray parameters (Sulzer Metco 9MB plasma system, Sulzer Metco, Westbury, New York, USA)

\begin{tabular}{lllllll}
$\mathbf{N}_{\mathbf{2}}$ & $\mathbf{H}_{\mathbf{2}}$ & CGF, $\mathbf{N}_{\mathbf{2}}$ & I & P & Feed rate & ND \\
\hline SLPM & SLPM & SLPM & A & $\mathrm{kW}$ & $\mathrm{g} \mathrm{min}^{-1}$ & $\mathrm{~mm}$ \\
35.4 & 8.0 & 5.2 & 500 & 39.3 & 46 & $\mathrm{~mm}$ \\
\hline
\end{tabular}

$\mathrm{N}_{2}$-primary plasma gas, $\mathrm{H}_{2}$ - secondary plasma gas, $\mathrm{CGF}$-carrier gas $\left(\mathrm{N}_{2}\right)$ flow, $\mathrm{I}$-current, $\mathrm{P}$-input power calculated using voltage measured at the power supply, ND—nozzle diameter, SD—standoff distance

Table 2 Chemical composition of powders (wt.\%)

\begin{tabular}{llll}
\hline & AE1 & AE2 & AE3 \\
\hline $\mathrm{Y}_{2} \mathrm{O}_{3}$ & 7.57 & 7.79 & 7.78 \\
$\mathrm{SiO}_{2}$ & $<0.01$ & 0.09 & 0.18 \\
$\mathrm{Al}_{2} \mathrm{O}_{3}$ & 0.05 & 0.2 & 0.09 \\
$\mathrm{TiO}_{2}$ & $<0.01$ & 0.08 & 0.04 \\
$\mathrm{Fe}_{2} \mathrm{O}_{3}$ & $<0.01$ & 0.01 & 0.02 \\
$\mathrm{CaO}$ & $<0.01$ & 0.01 & 0.02 \\
$\mathrm{HfO}$ & 1.89 & 1.84 & 1.76 \\
$\mathrm{MgO}$ & $<0.01$ & $<0.01$ & $<0.01$ \\
$\mathrm{ZrO}_{2}$ & Bal. & Bal. & Bal. \\
\hline
\end{tabular}

mild steel substrates, pre-coated with aluminum to facilitate de-bonding of the coating by treatment with concentrated hydrochloric acid.

\subsection{Heat Treatment and Dilatometry}

Detached coatings were isothermally heat treated in air at $1400{ }^{\circ} \mathrm{C}$. A heating rate of $20^{\circ} \mathrm{C} \mathrm{min}{ }^{-1}$ was used, while cooling after the heat treatment was carried out by simply removing the sample from the furnace. Phase constitution after heat treatment was checked using x-ray diffraction and it was concluded that the phase changes are expected to make only relatively small contributions to shrinkage (Ref 31). Dimensional changes during heat treatment were monitored using a DIL 402C Netzsch dilatometer (Selb, Germany). Dilatometry was performed in both inplane and through-thickness directions.

\subsection{Microstructural Examination}

Microstructural examinations were carried out using a JEOL 6340F FEG-SEM (Tokyo, Japan). To prevent charging, coatings were sputter coated with gold. A typical microstructure is shown in Fig. 1. Heat treatment results in grain growth, often bridging interfaces between splats, as shown in Fig. 2. There is also evidence of healing of microcracks. However, large voids remain relatively unaffected.

\subsection{Mercury Intrusion Porosimetry}

Mercury porosimetry was carried out using a Micromeritics Autopore IV facility (Norcross, GA 30093-1877, USA). Coating fragments of known total mass $(\sim 8 \mathrm{~g})$, with dimensions $\sim 5 \mathrm{~mm} \times 5 \mathrm{~mm} \times 2 \mathrm{~mm}$, were used. Estimates of the sample bulk volume and skeletal volume (and hence sample density) were obtained from mercury penetration volumes. The pressure required to enter pores of a specified width is given by the Washburn equation (Ref 32) for slit-like pores as follows:
$P=-\frac{2 \gamma \cos \theta}{D}$

where $P$ is the applied pressure, $\gamma$ is the surface tension of mercury (taken as $0.485 \mathrm{~N} \mathrm{~m}^{-1}$ ), $\theta$ is the contact angle (taken as $130^{\circ}$ ) and $D$ is the slit width. The penetrometer was progressively pressurized up to $\sim 200 \mathrm{MPa}$, with the penetration volume being monitored by measuring the capacitance of a co-axial capacitor formed by the intruding mercury and the conducting stem. With this applied pressure, pores down to a few $\mathrm{nm}$ in width could be detected. Both the pore size distribution and the total pore volume were measured. Estimates of sample skeletal and bulk densities were also made from pore volume measurements.

\subsection{Surface Area Measurement by Gas Adsorption}

A MicroMeritics TriStar 3000 (Norcross, GA 300931877 , USA) was used to measure the specific surface area of coatings. Coating fragments of known total mass $(\sim 10 \mathrm{~g})$, with dimensions $\sim 5 \mathrm{~mm} \times 5 \mathrm{~mm} \times 2 \mathrm{~mm}$, were used. They were thoroughly dried $\left(\sim 250{ }^{\circ} \mathrm{C}\right.$ overnight $)$ before measurement. The sample chambers were then cooled to liquid $\mathrm{N}_{2}$ temperature and evacuated. Nitrogen was introduced, in controlled pressure increments, and the equilibrated pressures measured and compared with the saturation pressure, to determine the quantities of adsorbed gas. The Brunauer-Emmett-Teller (BET) adsorption isotherm was then used to determine the specimen surface area.

\subsection{Stiffness Measurement}

Apparent Young's moduli in the in-plane direction were measured before and after heat treatment, using specimens with dimensions $100 \mathrm{~mm} \times 10 \mathrm{~mm} \times 1 \mathrm{~mm}$. These measurements were carried out using a customized four-point bending rig. The load was applied via weights on a counter-balanced pan, while displacements were measured using a scanning laser extensimeter. It was confirmed that only elastic deformation was taking place by checking the linearity and reversibility of the loaddisplacement plots. Stiffness data were also obtained by measurement of the resonant vibration frequency, using RFDA MF 23 equipment (IMCE, Diepenbeek, Belgium).

\subsection{Thermal Conductivity Measurement}

Through-thickness thermal conductivities of coatings were measured using specimens with dimensions $34 \mathrm{~mm} \times 28 \mathrm{~mm} \times 2 \mathrm{~mm}$. The HotDisk ${ }^{\circledR}$ method (Ref 33) was used. 


\section{Shrinkage, Surface Area, and Pore Size Distributions}

It should first be emphasized that, while dilatometry is a useful technique for monitoring of the shrinkage associated with sintering, it does not give complete information about sintering effects. It is well established (Ref 34) that some sintering mechanisms lead to densification (shrinkage), while others do not. The important point is whether material reaching the growing necks (high curvature regions) has come from regions located between the centers (of the dense particles), in which case the centers approach each other and densification occurs, or from other regions (e.g., regions already on the free surface), in which case it does not. In general, volume and grain boundary diffusion tend to contribute to densification, while surface diffusion does not. All types of diffusion, on the other hand, can contribute to surface area reduction. It can therefore be useful to obtain both shrinkage and surface area data.

Dilatometry data, for shrinkage in both in-plane and through-thickness directions, are shown in Fig. 3, for samples with three different impurity levels. It can be seen that shrinkage is anisotropic, being greater in the throughthickness direction. This is consistent with the fact that, while inter-splat voids and intra-splat microcrack openings are broadly similar in magnitude $(\sim 10-300 \mathrm{~nm})$, typical spacings between them are different $(\sim 1-2 \mu \mathrm{m}$, i.e., splat thickness, for the voids, compared with $\sim 5-10 \mu \mathrm{m}$ for the spacing between microcracks). Closure of the voids thus tends to generate greater (through-thickness) shrinkage than similar degrees of closure of microcracks, which causes in-plane shrinkage. It is also clear that higher levels of silica and alumina tend to cause enhanced rates of shrinkage, and that relatively small changes in the range concerned (e.g., cutting levels from $\sim 0.1-0.2$ wt. \% down to $\sim 0.01-0.05$ wt. $\%$ ) have a significant effect (factor of

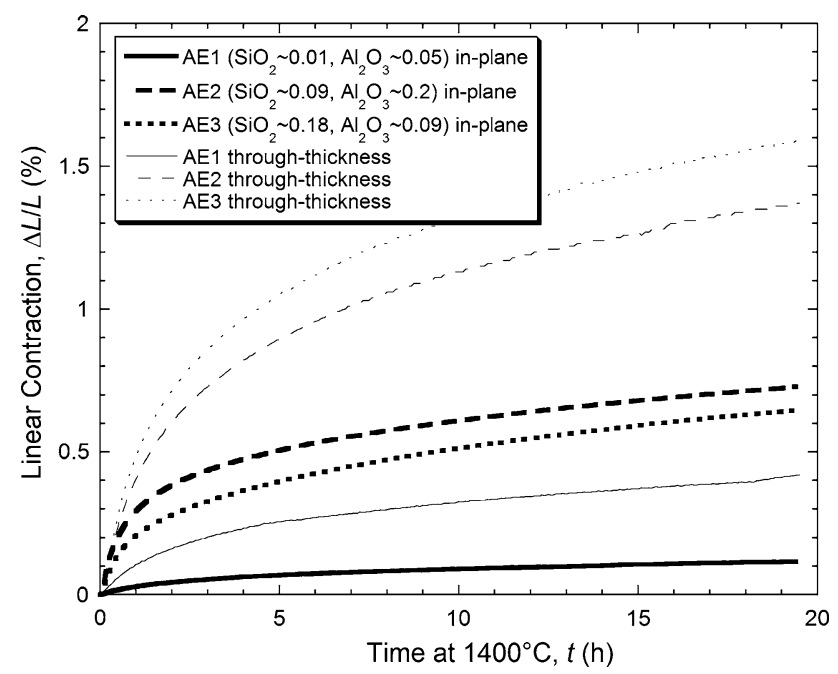

Fig. 3 Dilatometry data, showing the dimensional changes exhibited by YSZ coatings with different impurity (silica and alumina) levels during heat treatment at $1400{ }^{\circ} \mathrm{C}$ about 3-5). It would appear from these limited data that the sensitivity to impurity level is rather similar for alumina and silica, although the ratio of through-thickness to in-plane shrinkage rates seems to be somewhat higher when the silica content is greater.

Pore surface area measurements, for the same coating compositions, are shown in Fig. 4, before and after two heat treatments at $1400{ }^{\circ} \mathrm{C}$. It can be seen that these changes are broadly similar to the corresponding dimensional changes recorded by dilatometry. The reduction in surface area is more pronounced for coatings with higher alumina and silica content. This is consistent with the disappearance of fine scale porosity after $1 \mathrm{~h}$ at $1400^{\circ} \mathrm{C}$, observed with porosimetry (Fig. 5). It also suggests that volume and/or grain boundary diffusion are significant here, since if surface diffusion were dominant then it

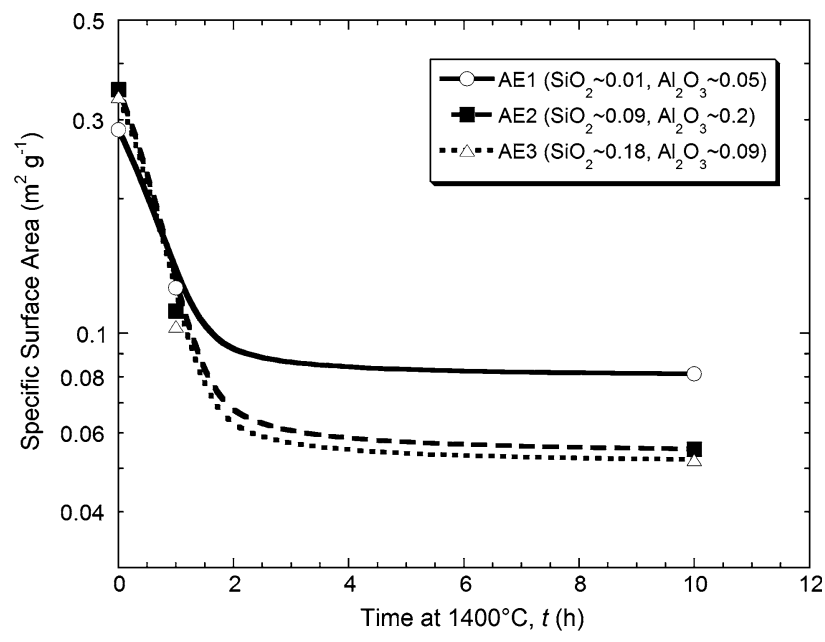

Fig. 4 BET (surface area) data, showing the changes exhibited by YSZ coatings with different impurity (silica and alumina) levels during heat treatment at $1400^{\circ} \mathrm{C}$

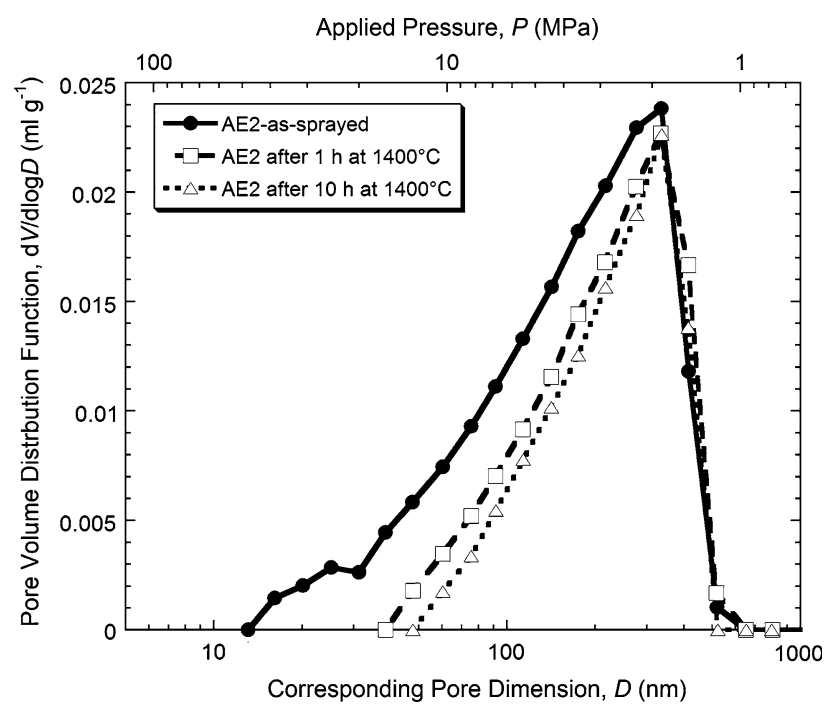

Fig. 5 Mercury porosimetry data, showing the pore size distributions exhibited by a YSZ coating before and after two different heat treatment at $1400{ }^{\circ} \mathrm{C}$ 
would be expected that the surface area reduction would be more pronounced than the shrinkage (see above). However, it should perhaps be noted here that liquid phase sintering might be contributing to the observed effects, particularly with the higher impurity levels. Little is known about the formation of vitreous phases in this system, although there are some indications that they can form (Ref 28, 30, 35). However, if substantial quantities were forming during the present experiments, then it would be expected that even the relatively large pores would start to disappear. In practice, there is no detectable change in the volume of such pores, which suggests that the vitreous phase content at high temperature is relatively low, although it should be noted that MIP is not well suited for relatively large pores, which require low infiltration pressures. This difficulty is partly associated with the "ink-bottle" effect (Ref 36). Nevertheless, it seems clear that these impurities significantly enhance the diffusion rates, probably for lattice, grain boundary, and surface diffusion.

\section{Stiffness and Conductivity}

While large globular pores remained unaffected by the heat treatment, fine scale porosity (microcracks and poor inter-splat contact), which are responsible for the high compliance, tend to be quickly removed. This results in a sharp increase in stiffness after short heat treatment times (Fig. 6). This is in agreement with previous observations (Ref 11, 17).

Locking of splats as a result of heat treatment also increases the inter-splat contact area, raising the thermal conductivity. It can be seen in Fig. 7 that the as-sprayed thermal conductivities of the three coatings are very similar. This suggests that it is predominantly the microstructure (splat and pore architecture) which tends to control the conductivity, with the presence of impurities (which might be expected to lower the lattice conductivity slightly) having little effect. However, the conductivity

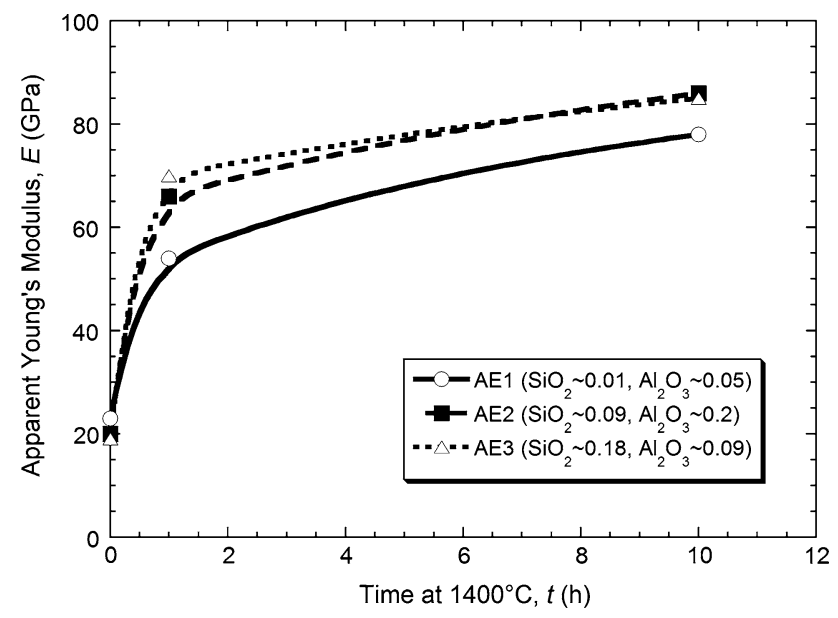

Fig. 6 In-plane stiffness of YSZ coatings, before and after heat treatments at $1400^{\circ} \mathrm{C}$

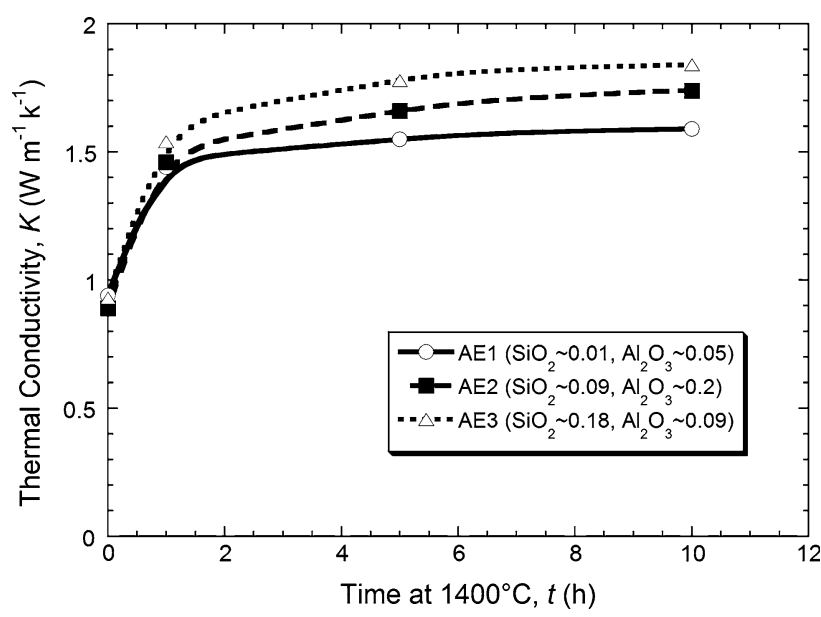

Fig. 7 Through-thickness thermal conductivity of YSZ coatings, before and after heat treatments at $1400{ }^{\circ} \mathrm{C}$

rises more rapidly during heat treatment for the specimens with higher impurity levels, since these accelerate the sintering and hence the rate at which the inter-splat area increases. This is consistent with predictions from an analytical model (Ref 37 ) for the thermal conductivity of these coatings, as a function of heat treatment.

\section{Conclusions}

The following conclusions can be drawn from this work, which has focused on plasma-sprayed zirconia- 8 wt. \% yttria coatings heat treated at $1400{ }^{\circ} \mathrm{C}$.

(a) Reducing the contents of alumina and silica, from $\sim 0.1-0.2$ wt. $\%$ down to $\sim 0.01-0.05$ wt. $\%$, effects a significant reduction in the sintering rates, as monitored by dilatometry, porosimetry, surface area measurement, stiffness, and thermal conductivity.

(b) This reduction in sintering rates is attributed to slower diffusion, with lattice, grain boundary and surface diffusion probably all affected. The fact that rates of surface area reduction reflect the rates of linear contraction suggests that lattice and/or grain boundary diffusion contribute strongly to the sintering mechanism, so it is unlikely that only surface diffusion is involved. It is possible that liquid phase sintering is taking place, particularly with the higher impurity levels, but it is not a dominant mechanism under the conditions studied.

(c) The sintering effects significant changes in pore architecture, with healing of intra-splat microcracks and enhanced inter-splat bonding. These are accompanied by pronounced grain growth. These changes lead to significant increases in both in-plane stiffness and through-thickness thermal conductivity. The latter is sensitive to increased inter-splat area, while the former is affected by both microcrack healing and improved inter-splat bonding. 


\section{Acknowledgments}

Funding for this work has been provided by an EPSRC Platform Grant (IOG), the Gates Foundation (SP), and the Basque Government (AC).

\section{References}

1. R.A. Miller, Thermal Barrier Coatings for Aircraft Engines: History and Directions, J. Therm. Spray Technol., 1997, 6(1), p 35-42

2. M. Tamura, M. Takahashi, J. Ishii, K. Suzuki, M. Sato, and K. Shimomura, Multilayered Thermal Barrier Coating for LandBased Gas Turbines, J. Therm. Spray Technol., 1999, 8(1), p 68-72

3. L. Singheiser, R. Steinbrech, W.J. Quadakkers, and R. Herzog, Failure Aspects of Thermal Barrier Coatings, Mater. High Temp., 2001, 18(4), p 249-259

4. D. Stover, G. Pracht, H. Lehmann, M. Dietrich, J.E. Doring, and R. Vassen, New Material Concepts for the Next Generation of Plasma Sprayed Thermal Barrier Coatings, J. Therm. Spray Technol., 2004, 13(1), p 76-83

5. A.J. Allen, J. Ilavsky, G.G. Long, J.S. Wallace, C.C. Berndt, and H. Herman, Microstructural Characterisation of Yttria-Stabilised Zirconia Plasma-Sprayed Deposits Using Multiple Small-Angle Neutron Scattering, Acta Mater., 2001, 49, p 1661-1675

6. A. Kulkarni, Z. Wang, T. Nakamura, S. Sampath, A. Goland, H. Herman, J. Allen, J. Ilavsky, G. Long, J. Frahm, and R.W. Steinbrech, Comprehensive Microstructural Characterization and Predictive Property Modeling of Plasma-Sprayed Zirconia Coatings, Acta Mater., 2003, 51(9), p 2457-2475

7. A. Kulkarni, J. Gutleber, S. Sampath, A. Goland, W.B. Lindquist, H. Herman, A.J. Allen, and B. Dowd, Studies of the Microstructure and Properties of Dense Ceramic Coatings Produced by High-Velocity Oxygen-Fuel Combustion Spraying, Mater. Sci. Eng. A - Struct., 2004, 369(1-2), p 124-137

8. P. Strunz, G. Schumacher, R. Vassen, and A. Wiedenmann, In Situ SANS Study of Pore Microstructure in YSZ Thermal Barrier Coatings, Acta Mater., 2004, 52, p 3305-3312

9. T.A. Dobbins, A.J. Allen, J. Ilavsky, G.G. Long, P.R. Jemian, A. Kulkarni, and H. Herman, Recent Development in the Characterization of Anizotropic Void Populations in Thermal Barrier Coatings Using Ultra-small Angle X-ray Scattering, Ceram. Eng. Sci Proc., 2003, 24(3), p 517-524

10. J. Ilavsky, C.C. Berndt, and J. Karthikeyan, Mercury Intrusion Porosimetry of Plasma-Sprayed Ceramic, J. Mater. Sci., 1997, 32(15), p 3925-3932

11. H.E. Eaton and R.C. Novak, Sintering Studies of Plasma Sprayed Zirconia, Surf. Coat. Technol., 1987, 32, p 227-236

12. H.C. Chen, E. Pfender, and J. Heberlein, Structural Changes in Plasma-Sprayed $\mathrm{ZrO}_{2}$ Coatings After Hot Isostatic Pressing, Thin Solid Films, 1997, 293(1-2), p 227-235

13. D.M. Zhu and R.A. Miller, Sintering and Creep Behaviour of Plasma-Sprayed Zirconia- and Hafnia-Based Thermal Barrier Coatings, Surf. Coat. Technol., 1998, 109(1-3), p 114-120

14. B. Siebert, C. Funke, R. Vassen, and D. Stover, Changes in Porosity and Young's Modulus Due to Sintering of Plasma Sprayed Thermal Barrier Coatings, J. Mater. Process Technol., $1999, \mathbf{9 3}, \mathrm{p} 217-223$

15. J. Ilavsky, G.G. Long, A.J. Allen, and C.C. Berndt, Evolution of the Void Structure in Plasma-Sprayed YSZ Deposits During Heating, Mater. Sci. Eng., 1999, 272(1), p 215-221

16. J. Ilavsky, J.K. Stalick, and J. Wallace, Thermal Spray YttriaStabilized Zirconia Phase Changes During Annealing, J. Therm. Spray Technol., 2001, 10(3), p 491-501

17. J.A. Thompson and T.W. Clyne, The Effect of Heat Treatment on the Stiffness of Zirconia Top Coats in Plasma-Sprayed TBCs, Acta Mater., 2001, 49(9), p 1565-1575
18. D. Stover and C. Funke, Directions of the Development of Thermal Barrier Coatings in Energy Applications, J. Mater. Process Technol., 1999, 93, p 195-202

19. V. Teixeira, M. Andritschky, H. Gruhn, W. Mallener, H.P. Buchkremer, and D. Stoever, Failure of Physical Vapor Deposition/Plasma-Sprayed Thermal Barrier Coatings During Thermal Cycling, J. Therm. Spray Technol., 2000, 9(2), p 191-197

20. D.M. Zhu and R.A. Miller, Thermal Conductivity and Elastic Modulus Evolution of Thermal Barrier Coatings Under High Heat Flux Conditions, J. Therm. Spray Technol., 2000, 9, p 175180

21. S.A. Tsipas, I.O. Golosnoy, R. Damani, and T.W. Clyne, The Effect of a High Thermal Gradient on Sintering and Stiffening in the Top Coat of a Thermal Barrier Coating (TBC) System, J. Therm. Spray Technol., 2004, 13(3), p 370-376

22. S.R. Choi, D.M. Zhu, and R.A. Miller, Effect of Sintering on Mechanical Properties of Plasma-Sprayed Zirconia-Based Thermal Barrier Coatings, J. Am. Ceram. Soc., 2005, 88(10), p 28592867

23. R. Hamacha, P. Fauchais, and F. Nardou, Influence of Dopant on the Thermal Properties of Two Plasma-Sprayed Zirconia Coatings 1. Relationship Between Powder Characteristics and Coating Properties, J. Therm. Spray Technol., 1996, 5(4), p 431-438

24. S. Sodeoka, M. Suzuki, K. Ueno, H. Sakuramoto, T. Shibata, and M. Ando, Thermal and Mechanical Properties of $\mathrm{ZrO}_{2}-$ $\mathrm{CeO}_{2}$ Plasma-Sprayed Coatings, J. Therm. Spray Technol., 1997, 6(3), p 361-367

25. M.N. Rahaman, J.R. Gross, R.E. Dutton, and H. Wang, Phase Stability, Sintering, and Thermal Conductivity of Plasma-Sprayed $\mathrm{ZrO}_{2}-\mathrm{Gd}_{2} \mathrm{O}_{3}$ Compositions for Potential Thermal Barrier Coating Applications, Acta Mater., 2006, 54(6), p 1615-1621

26. B.Z. Janos, E. Lugscheider, and P. Remer, Effect of Thermal Aging on the Erosion Resistance of Air Plasma Sprayed Ziconia Thermal Barrier Coating, Surf. Coat. Technol., 1999, 113(3), p 278-285

27. H.C. Chen, E. Pfender, and J. Heberlein, Plasma-Sprayed $\mathrm{ZrO}_{2}$ Thermal Barrier Coatings Doped with an Appropriate Amount of $\mathrm{SiO}_{2}$, Thin Solid Films, 1998, 315(1-2), p 159-169

28. R. Vassen, N. Czech, W. Mallener, W. Stamm, and D. Stoever, Influence of Impurity Content and Porosity of Plasma-Sprayed Yttria-Stabilized Zirconia Layers on the Sintering Behaviour, Surf. Coat. Technol., 2001, 141, p 135-140

29. K. Matsui, N. Ohmichi, M. Ohgai, N. Enomoto, and J. Hojo, Sintering Kinetics at Constant Rates of Heating: Effect of $\mathrm{Al}_{2} \mathrm{O}_{3}$ on the Initial Sintering Stage of Fine Zirconia Powder, J. Am. Ceram. Soc., 2005, 88(12), p 3346-3352

30. S. Stemmer, J. Vleugels, and O. Van Der Biest, Grain Boundary Segregation in High-Purity Yttria-Stabilized Tetragonal Zirconia Polygrystals (T-TZP), J. Eur. Ceram. Soc., 1998, 18, p 1565-1570

31. S. A. Tsipas, I. O. Golosnoy, R. Damani, and T. W. Clyne, The Effect of a High Thermal Gradient on Sintering and Stiffening in the Top Coat of a Thermal Barrier Coating System, J. Therm. Spray Technol., 2004, 13(3), p 370-376

32. E.W. Washburn, Note on a Method of Determining the Distribution of Pore Sizes in a Porous Materials, Proc. Natl. Acad. Sci. USA., 1921, 7, p 115-116

33. M. Gustavsson, E. Karawacki, and S.E. Gustafsson, Thermal Conductivity, Thermal Diffusivity, and Specific Heat of Thin Samples from Transient Measurements with Hot Disk Sensors, Rev. Sci. Inst., 1994, 65, p 3856-3859

34. M.F. Ashby, A First Report on Sintering Diagrams, Acta Metall. Mater., 1974, 22, p 275-289

35. S.M. Lakiza and L.M. Lopato, Stable and Metastable Phase Relations in the System Alumina-Zirconia-Yttria, J. Am. Ceram. Soc., 1997, 80(4), p 893-902

36. J. Van Brakel, S. Modry, and M. Svata, Mercury Porosimetry: State of the Art, Powder Technol., 1981, 29, p 1-12

37. I.O. Golosnoy, S.A. Tsipas, and T.W. Clyne, An Analytical Model for Simulation of Heat Flow in Plasma Sprayed Thermal Barrier Coatings, J. Therm. Spray Technol., 2005, 14(2), p 205-214 